\title{
Case Report \\ FOLFOX Induced Takotsubo Cardiomyopathy Treated with Impella Assist Device
}

\author{
Swethika Sundaravel, ${ }^{1}$ Abdulah Alrifai, ${ }^{2}$ Mohamad Kabach, ${ }^{2}$ and Waqas Ghumman ${ }^{2}$ \\ ${ }^{1}$ Internal Medicine, University of Miami, Palm Beach Regional Consortium, Atlantis, FL, USA \\ ${ }^{2}$ Cardiology, University of Miami, Palm Beach Regional Consortium, Atlantis, FL, USA \\ Correspondence should be addressed to Swethika Sundaravel; swethikaharini@gmail.com
}

Received 16 January 2017; Accepted 26 February 2017; Published 7 March 2017

Academic Editor: Markus Ferrari

Copyright (C) 2017 Swethika Sundaravel et al. This is an open access article distributed under the Creative Commons Attribution License, which permits unrestricted use, distribution, and reproduction in any medium, provided the original work is properly cited.

\begin{abstract}
Chemotherapy induced cardiotoxicity is becoming increasingly prevalent with several new agents being used recently. The incidence of Takotsubo cardiomyopathy due to 5-fluorouracil based chemotherapeutic regimens like FOLFOX is not uncommon. It is also seen with platinum based chemotherapy. Most of these patients have reversible cardiotoxicity and the cardiac function recovers within a short period with supportive treatment. Here we have a patient who presented with cardiogenic shock after 5 days of receiving FOLFOX regimen for colorectal adenocarcinoma. She was treated with a percutaneous left ventricular assist device, Impella CP, for hemodynamic support with excellent outcome.
\end{abstract}

\section{Case Description}

This is a 61-year-old woman with history of paroxysmal atrial flutter status afrer ablation who was recently diagnosed with poorly differentiated adenocarcinoma of colon status after hemicolectomy. She had no other past medical history and was not taking any medications. She was a nonsmoker and nonalcoholic and denied use of illicit drugs. She was started on adjuvant chemotherapy with FOLFOX (5FU + folinic acid + oxaliplatin). Patient was tolerating the regimen without any complications until day 5 when she started experiencing acute dyspnea and diaphoresis. She was rushed to the emergency department. She was found to be hypotensive and in profound respiratory distress from pulmonary edema with extensive crackles bilaterally on chest auscultation. She was tachypneic and her oxygen saturation was $72 \%$ with 5 liters of nasal oxygen. She had to intubated immediately.

Her ECG showed $\mathrm{T}$ inversions in the precordial leads and ST flattening in the inferolateral leads. Troponin was $0.41 \mathrm{ng} / \mathrm{mL}$ and trended up to $1.7 \mathrm{ng} / \mathrm{mL}$ in $12 \mathrm{hrs}$. NT-proBNP was $7392 \mathrm{pg} / \mathrm{mL}$. Chest X-ray revealed bilateral pulmonary edema. Bedside 2D transthoracic echocardiogram (Figure 1) was done which showed hyperdynamic contraction of the basal region and stunning of the apex with a left ventricular ejection fraction of 25-30\% (echo 1 month ago, before starting chemotherapy had normal ejection fraction).

She underwent cardiac catheterization (Figures 2 and 3) which revealed normal flow in all the coronary arteries and left ventriculogram ejection fraction of $20 \%$ (Figure 4). Left Ventricular End Diastolic Pressure (LVEDP) was $25 \mathrm{mmHg}$ and mean arterial pressure was less than $50 \mathrm{mmHg}$. Right heart catheterization demonstrated Pulmonary Capillary Wedge Pressure (PCWP) of $22 \mathrm{mmHg}$ with mean pulmonary artery pressure of $29 \mathrm{mmHg}$. Her initial cardiac index was $1.5-2.1 \mathrm{liters} / \mathrm{min} / \mathrm{m}^{2}$ and the cardiac output was $2.5-$ 3 liters $/ \mathrm{min}$. Lactic acid level in the blood was $6 \mathrm{mmol} / \mathrm{liter}$. An Impella CP assist device was placed for cardiac support. She also had a Swan-Ganz catheter in place for close hemodynamic monitoring. She also received diuresis and respiratory support. Over the next 3 days, she recovered remarkably. Her cardiac index improved to $2.5-3$ liters $/ \mathrm{min} / \mathrm{m}^{2}$ and the mean pulmonary artery pressure improved to $19 \mathrm{mmHg}$. The lactic acid in the blood also came down to $1.5 \mathrm{mmol} /$ liter. Echocardiogram revealed an ejection fraction of $35-40 \%$ with some contractile activity of the apical segments as well. The device was removed on day 3 . She was also slowly weaned 


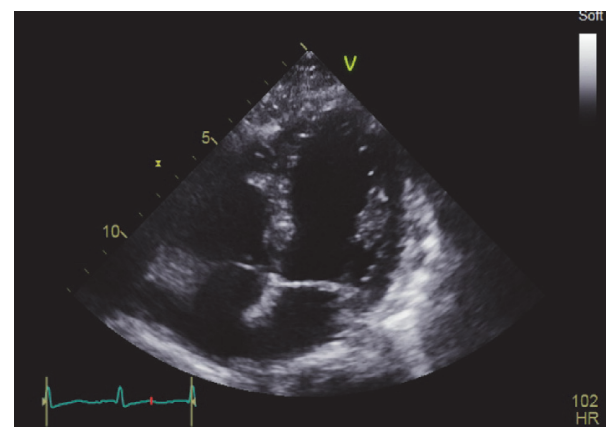

Trans-thoracic echo showing hypokinetic apex and hyperdynamic base of the heart

FIGURE 1: 4-chamber view transthoracic echocardiogram.

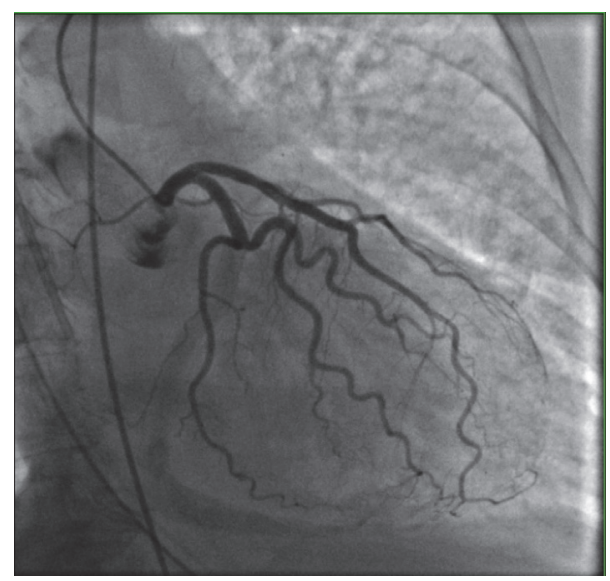

Cardiac catheterization revealing normal coronary anatomy

FIGURE 2: Left coronary artery.

off pressor support and extubated in the subsequent days. She was discharged on day 7 with beta-blockers, expected to follow up with oncology for a different regimen.

\section{Discussion}

Takotsubo cardiomyopathy is defined as nonischemic cardiomyopathy which occurs usually due to stress and increased catecholamine levels in the blood. Also known as apical ballooning syndrome, it is associated with a transient left ventricular hypokinesis with ECG changes and troponin elevation in the setting of nonobstructive coronary arteries and absence of pheochromocytoma or other usual causes of myocarditis [1]. It was first reported in Japan, in 1990 [2]. It is most prevalent in women over the age of 50 years, although it is not uncommon in men. 4 types of Takotsubo cardiomyopathy have been described so far: apical, midventricular, basal, and focal hypokinesis [3]. The incidence of Takotsubo cardiomyopathy after $5 \mathrm{FU}$ based chemotherapy is becoming increasingly prevalent [4]. Several cases have been reported in the literature $[5,6]$.

The pathogenesis of this condition is believed to be due to coronary vasospasm mediated $5 \mathrm{FU}$ and its metabolites

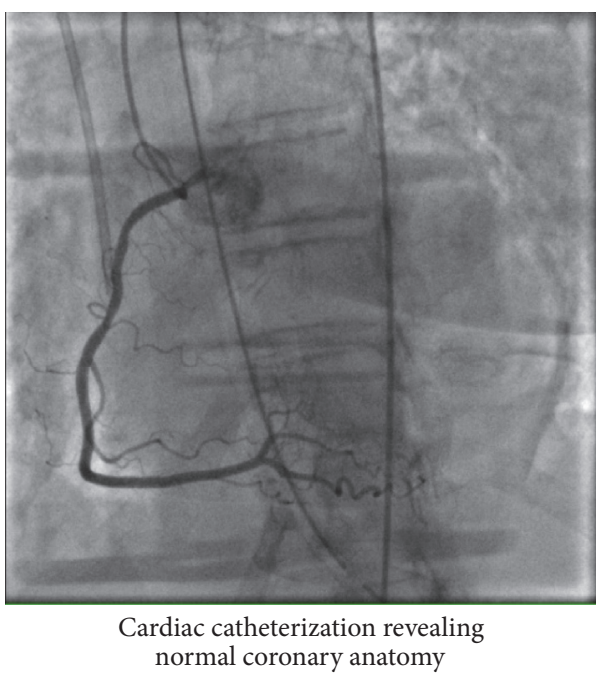

FIGURE 3: Right coronary artery.

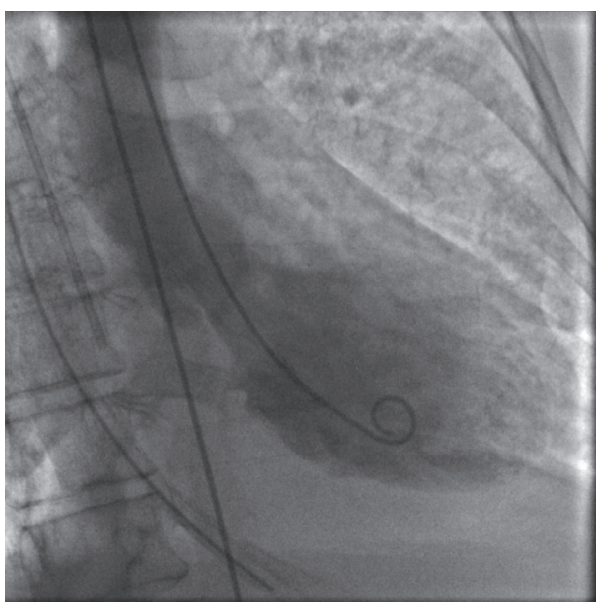

Left ventriculogram demonstrating apical ballooning

Figure 4: Left ventriculogram.

[7]. Other possible mechanisms are direct cardiotoxicity of $5 \mathrm{FU}$ on the myocytes and endothelial damage. The incidence of cardiotoxicity is less with bolus regimens [8] than with continuous infusions or with coadministration of leucovorin [9] or cisplatin [10]. The usual clinical presentation is anginalike chest pain during the infusion of the drug with concomitant ECG changes [11]. It can also present with arrhythmias and cardiac arrest in rare instances [12]. About 2\% of cases present in cardiogenic shock, like our patient [13]. Almost $95 \%$ of patients recover to normal cardiac function, but sometimes mortality rates can be as high as $8 \%$ [14]. Our patient was quite different in presentation from the rest. She presented on day 5 after the chemotherapy with cardiogenic shock.

The treatment is usually supportive with nitrates and calcium channel blockers in the acute phase along with hemodynamic support in the form of ventricular assist devices or Extracorporeal Membrane Oxygenation (ECMO) if needed. 
These patients must be started on beta-blockers for long-term treatment. In chemotherapy induced cases, discontinuing the offending agent is almost always inevitable. Following resolution of the acute cardiotoxic phase, reinstitution of the same agent has proven to be fatal in some cases [15] and recurrence of Takotsubo has also been reported [16]. Considering these life-threatening complications, it is not advisable to rechallenge the patient with the same chemotherapeutic agent [17].

The use of cardiac assist devices for acute cardiogenic shock is well known. There are several types of devices including Intra-Aortic Balloon Pumps (IABP), Impella devices, tandem heart, and Left Ventricular Assist Devices (LVAD). The use of Impella device for acute cardiogenic shock is becoming more popular because of its immediate augmentation of the left ventricular function and its ability to supplement the cardiac output to about $2.5-5$ liters $/ \mathrm{min}$. It is used regularly for acute coronary syndromes and nonischemic cardiomyopathies including Takotsubo cardiomyopathy [18, 19]. It is proven to be more effective, feasible, and safe compared to Intra-Aortic Balloon Pumps by providing superior hemodynamic support [20]. To our knowledge and on review of literature, there is no reported case of FOLFOX or chemotherapy induced Takotsubo cardiomyopathy that has been treated with Impella device. Our patient had severe cardiogenic shock with an EF of $20 \%$ which necessitated the Impella assist device. We used Impella $\mathrm{CP}$ which provided an additional cardiac output of about $2.5-3$ liters $/ \mathrm{min}$. The patient's cardiac function improved remarkably in 3 days and the device was removed. There were no complications encountered.

\section{Conclusion}

5-Fluorouracil based chemotherapeutic regimens are extremely potent in treating several cancers including high grade colorectal malignancies. The most important and most dangerous side-effect of this drug is the cardiotoxicity which can manifest in many ways ranging from subtle angina to florid cardiogenic shock and cardiac arrest from ventricular fibrillation. Several other chemotherapeutic agents like platinum based therapies are also associated with cardiotoxicity. Cardiac oncology is a relatively new field of cardiology dealing with cancer patients who have suffered cardiotoxicity from chemotherapy. Several novel strategies have been tested to minimize the side-effects of these drugs including prophylactic nitrates, calcium channel blockers, and ACE inhibitors/ARBs to these patients, but, so far, none of them have been proven effective except dose reduction of the chemotherapeutic agent and bolus regimens.

The treatment of acute cardiogenic shock has also come a long way with the discovery of new percutaneous ventricular assist devices which have proven to be very effective in the decompensated setting. The use of these devices in chemotherapy induced cardiomyopathy has shown to decrease the number of hospital/ICU days and result in speedy recovery. More randomized trials and systematic reviews are required to analyze the overall use of such devices.

\section{Conflicts of Interest}

The authors declare that there are no conflicts of interest regarding the publication of this paper.

\section{References}

[1] A. Prasad, A. Lerman, and C. S. Rihal, "Apical ballooning syndrome (Tako-Tsubo or stress cardiomyopathy): a mimic of acute myocardial infarction," American Heart Journal, vol. 155, no. 3, pp. 408-417, 2008.

[2] H. T. H. Sato, T. Uchida, K. Dote, and M. Ishihara, "Tako-tsubolike left ventricular dysfunction due to multivessel coronary spasm," in Clinical Aspect of Myocardial Injury: From Ischemia to Heart Failure, K. Kodama, K. Haze, and M. Hori, Eds., pp. 56-64, Kagakuhyoronsha Publishing, Tokyo, Japan, 1990.

[3] C. Templin, J. R. Ghadri, J. Diekmann et al., "Clinical features and outcomes of takotsubo (stress) cardiomyopathy," The New England Journal of Medicine, vol. 373, pp. 929-938, 2015.

[4] G. Segalini, R. Labianca, G. D. Beretta et al., "Cardiotoxicity of 5-fluorouracil. Personal cases and review of the literature," Giornale Italiano di Cardiologia, vol. 17, no. 9, pp. 781-785, 1987.

[5] M. Gianni, F. Dentali, A. M. Grandi, G. Sumner, R. Hiralal, and E. Lonn, "Apical ballooning syndrome or takotsubo cardiomyopathy: a systematic review," European Heart Journal, vol. 27, no. 13, pp. 1523-1529, 2006.

[6] P. Tsibiribi, J. Descotes, C. Lombard-Bohas et al., "Cardiotoxicity of 5-fluorouracil in 1350 patients with no prior history of heart disease," Bull Cancer, vol. 93, no. 3, pp. E27-E30, 2006.

[7] T. Südhoff, M.-D. Enderle, M. Pahlke et al., "5-Fluorouracil induces arterial vasocontractions," Annals of Oncology, vol. 15, no. 4, pp. 661-664, 2004.

[8] S. A. Jensen and J. B. Sørensen, "Risk factors and prevention of cardiotoxicity induced by 5-fluorouracil or capecitabine," Cancer Chemotherapy and Pharmacology, vol. 58, no. 4, pp. 487493, 2006.

[9] C. Schober, E. Papageorgiou, A. Harstrick et al., "Cardiotoxicity of 5-fluorouracil in combination with folinic acid in patients with gastrointestinal cancer," Cancer, vol. 72, no. 7, pp. 22422247, 1993.

[10] C. Kosmas, M. S. Kallistratos, P. Kopterides et al., "Cardiotoxicity of fluoropyrimidines in different schedules of administration: a prospective study," Journal of Cancer Research and Clinical Oncology, vol. 134, no. 1, pp. 75-82, 2008.

[11] M. A. Ozturk, O. Ozveren, V. Cinar, B. Erdik, and B. Oyan, "Takotsubo syndrome: an underdiagnosed complication of 5fluorouracil mimicking acute myocardial infarction," Blood Coagulation and Fibrinolysis, vol. 24, no. 1, pp. 90-94, 2013.

[12] K. Knott, N. Starling, S. Rasheed et al., "A case of Takotsubo syndrome following 5-fluorouracil chemotherapy," International Journal of Cardiology, vol. 177, no. 2, pp. e65-e67, 2014.

[13] A. Polk, M. Vaage-Nilsen, K. Vistisen, and D. L. Nielsen, "Cardiotoxicity in cancer patients treated with 5-fluorouracil or capecitabine: a systematic review of incidence, manifestations and predisposing factors," Cancer Treatment Reviews, vol. 39, no. 8, pp. 974-984, 2013.

[14] M. W. Saif, M. M. Shah, and A. R. Shah, "Fluoropyrimidineassociated cardiotoxicity: revisited," Expert Opinion on Drug Safety, vol. 8, no. 2, pp. 191-202, 2009.

[15] C. Basselin, T. Fontanges, J. Descotes et al., "5-fluorouracilinduced tako-tsubo-like syndrome," Pharmacotherapy, vol. 31, no. 2 , article 226, 2011. 
[16] K. Becker, J. F. Erckenbrecht, D. Häussinger, and T. Frieling, "Cardiotoxicity of the antiproliferative compound fluorouracil," Drugs, vol. 57, no. 4, pp. 475-484, 1999.

[17] M. F. Sorrentino, J. Kim, A. E. Foderaro, and A. G. Truesdell, "5-fluorouracil induced cardiotoxicity: review of the literature," Cardiology Journal, vol. 19, no. 5, pp. 453-458, 2012.

[18] T. Hamid, J. Eichhöfer, D. Fraser et al., "Use of the impella left ventricular assist device as a bridge to recovery in a patient with cardiogenic shock related to takotsubo cardiomyopathy," Journal of Clinical \& Experimental Cardiology, vol. 4, no. 5, article 246, 2013.

[19] M. Cena, F. Karam, R. Ramineni, W. Khalife, and A. Barbagelata, "New impella cardiac power device used in patient with cardiogenic shock due to nonischemic cardiomyopathy," International Journal of Angiology, vol. 25, no. 4, pp. 258-262, 2016.

[20] M. Seyfarth, D. Sibbing, I. Bauer et al., "A randomized clinical trial to evaluate the safety and efficacy of a percutaneous left ventricular assist device versus intra-aortic balloon pumping for treatment of cardiogenic shock caused by myocardial infarction," Journal of the American College of Cardiology, vol. 52, no. 19, pp. 1584-1588, 2008. 


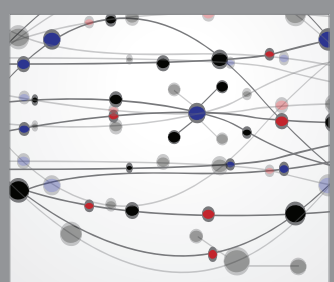

The Scientific World Journal
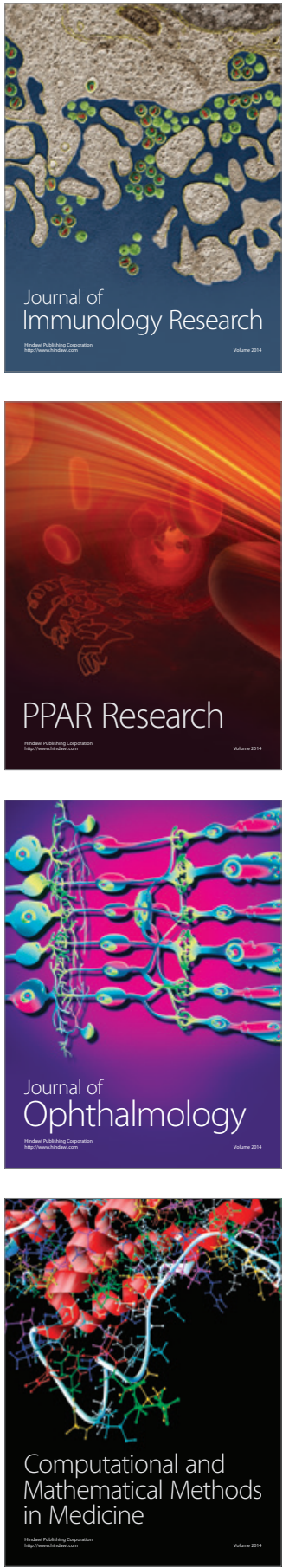

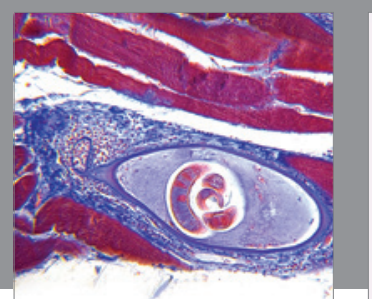

Gastroenterology Research and Practice
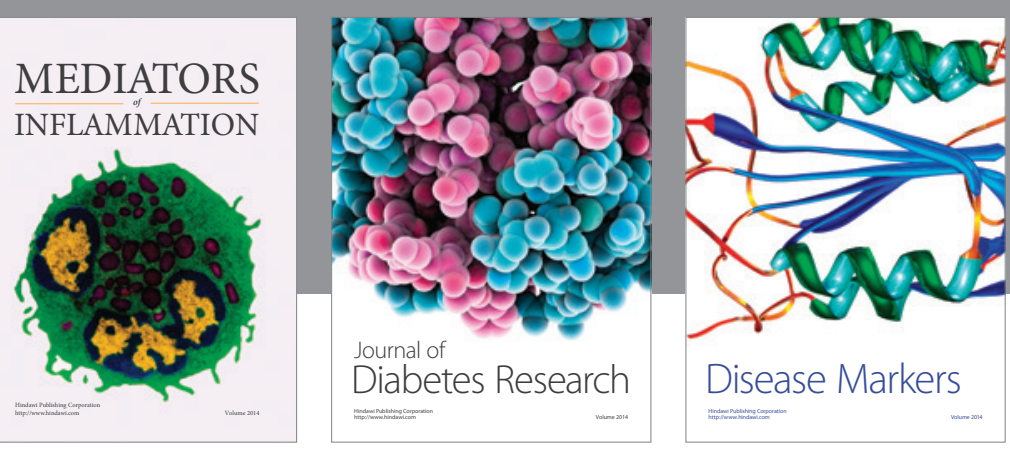

Disease Markers

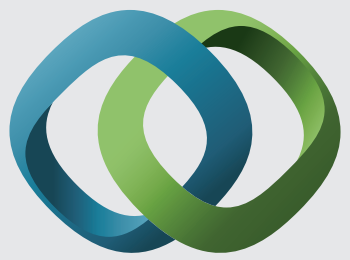

\section{Hindawi}

Submit your manuscripts at

https://www.hindawi.com
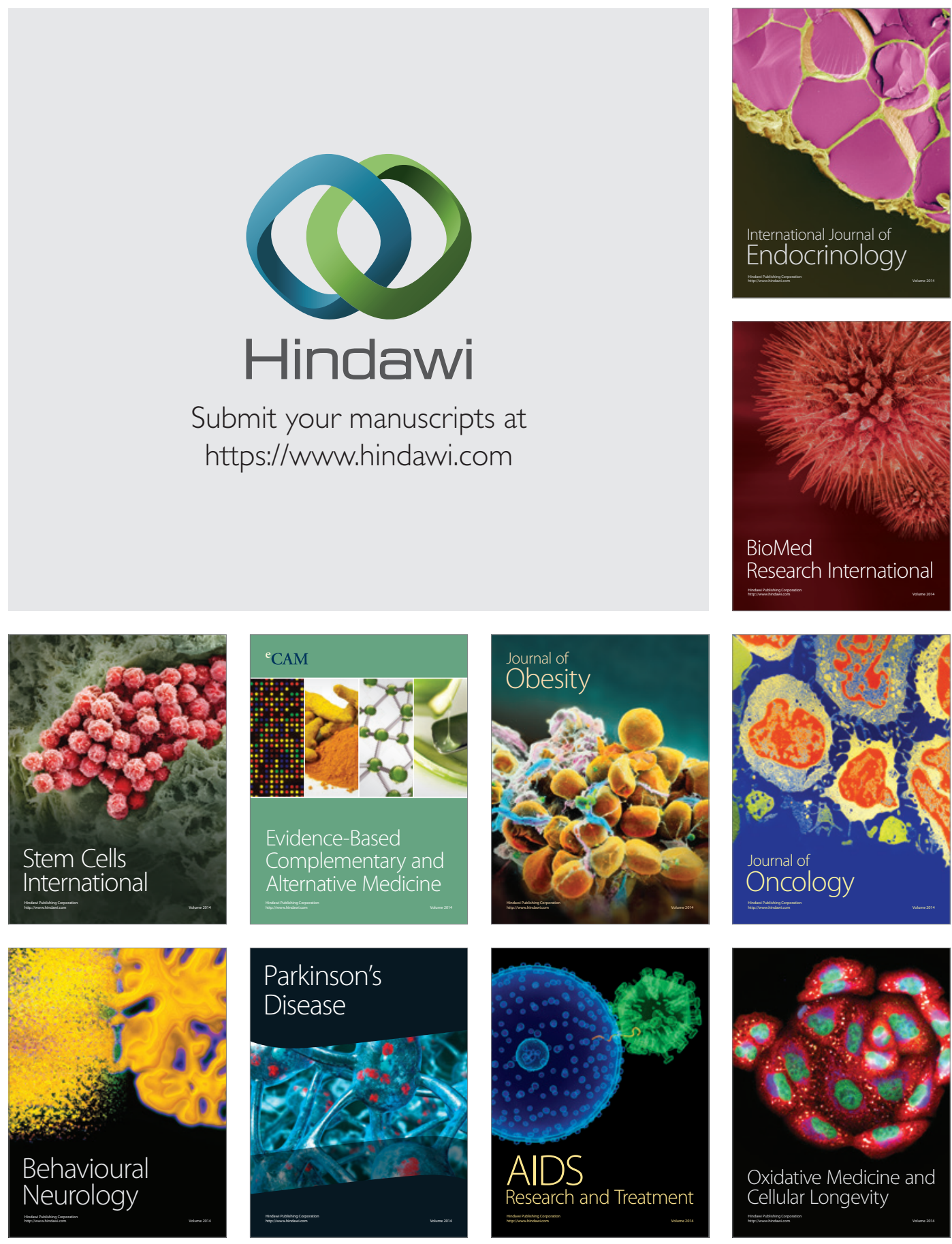